\title{
Three-Versus Two-Dimensional Sonographic Biometry in the Third Trimester of Pregnancy for Predicting Birth Weight and Macrosomia in Diabetic Pregnancies
} Kamel Nourel-Deen Abdul-Galeel, Abd Elmonsef Abd Elhamed Sedek, Karim Gamal Radwan*

Department of Obstetrics \& Gynecology, Faculty of Medicine, Al-Azhar University

*Corresponding author: Karim Gamal Radwan, Mobile: (+20)01286245843, E-Mail: gamalkarim16@gmail.com

\begin{abstract}
Background: diabetes is the most common metabolic disorder affecting pregnancy. Its prevalence seems to be growing in parallel with the epidemics of overweight and obesity. It's considered a modern epidemic disease that affects about $8.3 \%$ of adults (accounts for 382 million people of the global population) and $46 \%$ of cases are estimated to be undiagnosed. Recognizing and treating diabetes or any degree of glucose intolerance in pregnancy results in lowering maternal and fetal complications. Objective: our aim is to test the hypothesis that incorporating 3D fractional thigh volume would be superior to conventional 2D biometry for predicting birth weight and macrosomia in diabetic pregnancies.

Patients and Methods: the study was done on 160 pregnant women suffering from pre-gestational or gestational diabetes at El-Hussien and Sayed Galal Hospitals. All women were evaluated by full obstetrical history taking, physical examination, pelvic examination, transabdominal ultrasound, routine laboratory investigations and assessment of the route of delivery. Results: one-fifth of the patients had macrosomia, and four fifths had no macrosomia. There were no statistical significant differences between macrosomia group and no macrosomia group in maternal age, parity, body mass index, obesity, diabetes, gestational age and gestational age at delivery. The mean \pm SD was lower for the $2 \mathrm{D}$ than the $3 \mathrm{D}$ projected estimate. Our study showed that there were statistical high significant regarding birth weight at delivery and difference from $2 \mathrm{D} / 3 \mathrm{D}(\mathrm{p}<0.001)$.

Conclusion: we suggest that 2D sonography should remain the standard of care for predicting birth weight and macrosomia in diabetic pregnancies.

Keywords: Three-Versus Two-Dimensional Sonographic Biometry Trimester, Pregnancy for Predicting Birth Weight, Diabetic Pregnancies.
\end{abstract}

\section{INTRODUCTION}

Diabetes is the most common metabolic disorder that affects pregnancy. Its prevalence appears to be increasing in parallel with epidemics of overweight and obesity. A recent epidemic disease affects about $8.3 \%$ of adults, representing 382 million people worldwide, and it is estimated that $46 \%$ of cases are currently not diagnosed. Recognizing and treating diabetes or any degree of glucose intolerance in pregnancy reduces maternal and fetal complications ${ }^{(\mathbf{1})}$.

Pre-gestational diabetes (i.e., diabetes diagnosed before pregnancy, type 1 or type 2 diabetes mellitus) comprises approximately 13 percent of all diabetes in pregnancy, while gestational diabetes mellitus (GDM) is diabetes diagnosed in the second or third trimester of pregnancy that is not clearly overt diabetes" (2).

Fetal macrosomia is a common adverse infant outcome of GDM if unrecognized and untreated in time. For the infant, macrosomia increases the risk of shoulder dystocia, clavicle fractures and brachial plexus injury and increases the rate of admissions to the neonatal intensive care unit. For the mother, the risks associated with macrosomia are cesarean delivery, postpartum hemorrhage and vaginal lacerations. Infants of women with GDM are at an increased risk of becoming overweight or obese at a young age (during adolescence) and are more likely to develop type II diabetes later in life. Besides, the findings of several studies that epigenetic alterations of different genes of the fetus of a GDM mother in utero could result in the transgenerational transmission of GDM and type II diabetes are of concern ${ }^{(3)}$.

Fetal macrosomia, defined as fetal weight exceeding 4000 or $4500 \mathrm{~g}$ regardless of gestational age, is one of the most common complications of GDM and is associated with increased risks of neonatal and maternal morbidity, including shoulder dystocia, birth trauma, perineal lacerations, and cesarean delivery. Diabetes, especially when poorly controlled, is a major risk factor for fetal macrosomia. This association is partially explained by excessive growth from elevated maternal plasma glucose levels, resulting in elevated fetal insulin and insulin-like growth factor levels, which stimulate glycogen synthesis, fat deposition, and fetal growth ${ }^{(4)}$.

Moreover, neonates of diabetic mothers of the same birth weight are at higher risk for shoulder dystocia compared to those of nondiabetic mothers because of different distributions of body fat ${ }^{(5)}$.

Three-dimensional (3D) demonstrated a significant improvement over 2D biometry when fractional thigh volume, a soft tissue parameter based on $50 \%$ of the femur diaphysis length from 3D sonography, was incorporated into 2D biometry. To obtain fractional ThiV value, the collected volume data was reopened by using $4 \mathrm{D}$ view program, version 12 (GE medical system) under the fractional limb volume mode. After placing the caliper at both sides of the 
femur, the software automatically divided the femur into five transverse planes. By completely tracing the circumference of each slice, the fractional thigh volume will be calculated based on $50 \%$ of femur length (6). Two-dimensional and 3D sonographic examinations were performed for fetal biometry and fractional thigh volumes at 34 to 37 weeks. Fetal weight was estimated by Hadlock's 2D formula IV, which uses only $2 \mathrm{D}$ biometry which incorporates $3 \mathrm{D}$ fractional thigh volume and $2 \mathrm{D}$ biometry. The gestation-adjusted projection method was used to ${ }^{\bullet}$ estimate predicted birth weights from $2 \mathrm{D}$ and $3 \mathrm{D} \cdot$ estimates. The primary outcome was fetal macrosomia, which was defined as birth weight of $4000 \mathrm{~g}$ or higher ${ }^{(7)}$.

\section{AIM OF THE WORK}

The aim of this study is to test the hypothesis that incorporating 3D fractional thigh volume would be superior to conventional 2D biometry for predicting birth weight and macrosomia in diabetic pregnancies.

\section{PATIENTS AND METHODS}

(A) Technical design:

(1) Site of the study: El-Hussien and Sayed Galal Hospitals. The study was approved by the Ethics Board of Al-Azhar University and an informed written consent was taken from each participant in the study.

(2) Design of the study: Prospective cohort trial.

(3) Sample size: The study population was 160 pregnant women suffering from pre-gestational or gestational diabetes.

(4) Inclusion criteria: Patients were selected on the basis of the following criteria:

- Women diagnosed with pre-GDM and GDM in the current pregnancy.

- Diabetic patients diagnosed by 2-hour glucose tolerance test (after fasting the night and giving a sample of blood then a 75 gram glucose solution consumed orally). One hour and two hours after consumption blood draws are taken to measure blood glucose.

- If levels are higher than normal at any stage of the test, diabetes is definitively diagnosed. Normal value ranges are: oFasting values: $92 \mathrm{mg} / \mathrm{dl}$ or $5.1 \mathrm{mmol} / \mathrm{L}$. oOne-hour values: $180 \mathrm{mg} / \mathrm{dl}$ or $10 \mathrm{mmol} / \mathrm{L}$. o2-hour values: $153 \mathrm{mg} / \mathrm{dl}$ or $8.5 \mathrm{mmol} / \mathrm{L}$.

- Age from 18 to 35 years.

- Gestational age more than 36 weeks verified by LMP and/or first trimester ultrasound when available.

- Singleton pregnancy in vertex presentation without fetal anomalies.

- All cases were done in Obstetrics and Gynecology Department at Sayed Galal and El-Hussein's Hospitals by GE Voluson E6 ultrasound. The Voluson E6 supports a wide range of $2 \mathrm{D}$ and $3 \mathrm{D}$ probes to help meet the unique and varied clinical needs. When combined with the advanced Radiance System Architecture of the VOluson Expert Series probes produce excellent images with ease (Voluson GE E6).

(5) Exclusion criteria:

Multiple pregnancies.

- Age $<18$ or $>35$ years.

Gestational diabetes associated with hypertension.

Morbid obesity.

Congenital anomalies.

- Pregnant women with gestational age less than 36 weeks.

(B) Plan of the study:

All women were evaluated by:

A. Full obstetrical history taking including symptoms of diabetes (polyuria, polydipsia and polyphagia).

B. Physical examination:

1) General examination: The body mass index.

2) Abdominal examination: Inspection, superficial and deep palpation (to assess fundal level, fundal grip, umbilical grip and first and second pelvic grips), percussion and auscultation.

C. Pelvic examination: Including assessment of subpubic angle, uterine size, cervical consistency, dilatation, effacement and direction and fetal head engagement.

D. Transabdominal ultrasound: To assess gestational age, fetal body weight, any fetal anomaly and amniotic fluid index.

E. Routine laboratory investigations: In the form of hemoglobin level, hematocrit value, full laboratory chemistry and 75-gm oral glucose tolerance test.

\section{F. Assessment of the route of delivery for all cases.}

\section{Statistical analysis}

Inferential analyses were done for quantitative variables using independent t-test in cases of two independent groups, ANOVA test for more than two independent groups with post hoc Tuky's test. In qualitative data, inferential analyses for independent variables were done using Chi square test for differences between proportions and Fisher's Exact test for variables with small expected numbers. Logistic regression was done for factors affecting clinical and completed first trimester pregnancy among the studied cases. The level of significance was taken at $\mathrm{P}$ value $<0.050$ is significant, otherwise is nonsignificant.

Data management: Data were collected, summarized and tabulated on collection sheets. Data were entered into computer Microsoft Excel sheets with appropriate tabulation and graphical presentation. 
RESULTS

Table (1): Baseline characteristics of the study participants

\begin{tabular}{|c|c|}
\hline & $n=160$ \\
\hline $\begin{array}{l}\text { Maternal age (years) } \\
\text { Mean } \pm \text { SD } \\
\text { Range }\end{array}$ & $\begin{array}{c}29.6 \pm 3 \\
24-35\end{array}$ \\
\hline $\begin{array}{l}\text { Primiparous } \\
\text { Multiparous }\end{array}$ & $\begin{array}{l}72(45 \%) \\
88(55 \%)\end{array}$ \\
\hline BMI $\left(\mathbf{k g} / \mathbf{m}^{2}\right)$ & $\begin{array}{c}32.6 \pm 3.7 \\
26-39.5\end{array}$ \\
\hline Obesity (BMI > $\left.30 \mathrm{~kg} / \mathrm{m}^{2}\right)$ & $112(70 \%)$ \\
\hline Diabetes type & $\begin{array}{l}96(60 \%) \\
64(40 \%)\end{array}$ \\
\hline $\begin{array}{c}\text { Gestational age at sonography (weeks) } \\
\text { Mean } \pm \text { SD } \\
\text { Range }\end{array}$ & $\begin{array}{c}36.9 \pm 0.8 \\
36-38\end{array}$ \\
\hline $\begin{array}{c}\text { Gestational age at delivery (weeks) } \\
\text { Mean } \pm \text { SD } \\
\text { Range }\end{array}$ & $\begin{array}{c}38.8 \pm 0.7 \\
38-40\end{array}$ \\
\hline
\end{tabular}

This table shows that the age of the studied group ranged from 24 to 35 years with mean of 29.6 years. Regarding parity, $45 \%$ of cases were primiparous and $55 \%$ of them were multiparous. The mean gestational ages at sonographic biometry and delivery were 36.9 and 38.8 weeks, respectively.

Table (2): Baseline data according to macrosomia

\begin{tabular}{|c|c|c|c|}
\hline & $\begin{array}{l}\text { crosomia } \\
(n=32)\end{array}$ & $\begin{array}{l}\text { No macrosomia } \\
(\mathrm{n}=128)\end{array}$ & $\mathbf{p}$ \\
\hline Maternal age (years) & $29.9 \pm 1.8$ & $29.5 \pm 3.3$ & $0.5(\mathrm{NS})$ \\
\hline $\begin{array}{c}\text { Parity } \\
\\
\\
\begin{array}{l}\text { Primiparous } \\
\text { Multiparous }\end{array}\end{array}$ & $\begin{array}{l}13(40.6 \%) \\
19(59.4 \%)\end{array}$ & $\begin{array}{l}59(46.1 \%) \\
69(53.9 \%)\end{array}$ & $0.57(\mathrm{NS})$ \\
\hline BMI $\left(\mathbf{k g} / \mathbf{m}^{2}\right)$ & $33.1 \pm 4$ & $32.5 \pm 3.6$ & $0.44(\mathrm{NS})$ \\
\hline Obesity & $26(81.3 \%)$ & $86(67.2 \%)$ & $0.12(\mathrm{NS})$ \\
\hline $\begin{array}{c}\text { Diabetes type } \\
\text { Pregestational } \\
\text { Gestational }\end{array}$ & $\begin{array}{l}15(46.9 \%) \\
17(53.1 \%)\end{array}$ & $\begin{array}{l}81(63.3 \%) \\
47(36.7 \%)\end{array}$ & 0.09 (NS) \\
\hline Gestational age & $36.8 \pm 0.7$ & $36.9 \pm 0.8$ & $0.33(\mathrm{NS})$ \\
\hline Gestational age at delivery & $38.8 \pm 0.7$ & $38.9 \pm 0.7$ & $0.55(\mathrm{NS})$ \\
\hline
\end{tabular}

This table shows that there were no statistical significant differences between macrosomia group and no macrosomia group in maternal age, parity, body mass index, obesity, diabetes, gestational age and gestational age at delivery.

Table (3): Birth weight at delivery and difference from 2D/3D

\begin{tabular}{|c|c|c|c|}
\hline \multirow{2}{*}{ Birth weight } & Mean \pm SD & $3.86 \pm 0.33$ & p \\
\cline { 2 - 3 } & Range & $3.25-4.6$ & \multirow{2}{*}{} \\
\hline $\begin{array}{c}\text { Difference from projected 2D } \\
\text { estimated }\end{array}$ & Mean \pm SD & $0.06 \pm 0.24$ & \multirow{2}{*}{$<0.001$ (HS) } \\
\cline { 2 - 3 } $\begin{array}{c}\text { Difference from projected 3D } \\
\text { estimated }\end{array}$ & Reange \pm SD & $-0.65-0.3 \pm 0.25$ & \multirow{2}{*}{$<0.001$ (HS) } \\
\cline { 2 - 3 } & Range & $-0.85-0.4$ & \\
\hline
\end{tabular}

This table shows that there were statistical high significant regarding birth weight at delivery and difference from 2D/3D $(\mathrm{p}<0.001)$. 
Table (4): Correlation between estimated weight 2D and birth weight

\begin{tabular}{|c|c|c|}
\hline Estimated weight 2D & r & p \\
\hline Birth weight & 0.79 & $<0.001(\mathrm{HS})$ \\
\hline
\end{tabular}

This table shows that there was statistically a high significant positive correlation between estimated weight $2 \mathrm{D}$ and birth weight $(\mathrm{p}<0.001)$.

Table (5): Correlation between estimated weight 3D and birth weight

\begin{tabular}{|c|c|c|}
\hline Estimated weight 3D & r & p \\
\hline Birth weight & 0.7 & $<0.001$ (HS) \\
\hline
\end{tabular}

This table shows that there was statistically a high significant positive correlation between estimated weight $3 \mathrm{D}$ and birth weight $(\mathrm{p}<0.001)$.

Table (6): Validity of 2D and 3D sonography for macrosomia $>4000 \mathrm{gm}$ in diabetic pregnancies

\begin{tabular}{|c|c|c|}
\hline & $\begin{array}{c}\text { Projected 2D } \\
\text { estimated }\end{array}$ & $\begin{array}{c}\text { Projected 3D } \\
\text { estimated }\end{array}$ \\
\hline Sensitivity & $81.3 \%$ & $78.1 \%$ \\
\hline Specificity & $78.9 \%$ & $77.3 \%$ \\
\hline PPV & $49.1 \%$ & $46.3 \%$ \\
\hline NPV & $94.4 \%$ & $93.4 \%$ \\
\hline Accuracy & $79.3 \%$ & $77.5 \%$ \\
\hline
\end{tabular}

The sensitivity, specificity, PPV, NPV and accuracy for predicting macrosomia $>4000 \mathrm{gm}$ in diabetic pregnancies were $81.3 \%, 78.9 \%, 49.1 \%$, $94.4 \%$ and $79.3 \%$ for $2 \mathrm{D}$ biometry and $78.1 \%, 77.3 \%$, $46.3 \%, 93.4 \%$ and $77.5 \%$ for 3D biometry.

Table (7): Validity of 2D and 3D sonography for macrosomia $>4500 \mathrm{gm}$ in diabetic pregnancies

\begin{tabular}{|c|c|c|}
\hline & $\begin{array}{c}\text { Projected 2D } \\
\text { estimated }\end{array}$ & $\begin{array}{c}\text { Projected 3D } \\
\text { estimated }\end{array}$ \\
\hline Sensitivity & $69.2 \%$ & $76.9 \%$ \\
\hline Specificity & $89.1 \%$ & $88.4 \%$ \\
\hline PPV & $36 \%$ & $37 \%$ \\
\hline NPV & $97 \%$ & $97.7 \%$ \\
\hline Accuracy & $87.5 \%$ & $87.5 \%$ \\
\hline
\end{tabular}

The sensitivity, specificity, PPV, NPV and accuracy for predicting macrosomia $>4500 \mathrm{gm}$ in diabetic pregnancies were $69.2 \%, 89.1 \%, 36 \%, 97 \%$ and $87.5 \%$ for 2D biometry and $76.9 \%, 88.4 \%, 37 \%$, $97.7 \%$ and $87.5 \%$ for 3D biometry.

\section{DISCUSSION}

Birth weight (BW) is an important predictive parameter of neonatal outcome, and its estimation helps to determine obstetric management. Accurate prenatal estimation of birth weight would be extremely useful in the management of delivery ${ }^{(8)}$. The accuracy of the sonographically estimated fetal weight (EFW) in the diagnosis of macrosomia (birth weight [BW] $\geq 4000 \mathrm{~g}$ ) is suboptimal, with positive predictive values (PPVs) ranging from $38 \%$ to $67 \%$. Macrosomia is associated with both maternal and fetal morbidities, including increasing rates of surgical delivery, obstetric lacerations, brachial plexus injuries, and intrauterine fetal demise ${ }^{(\mathbf{9})}$.

Diabetes, especially when poorly controlled, is a major risk factor for fetal macrosomia. This association is partially explained by excessive growth from elevated maternal plasma glucose levels, resulting in elevated fetal insulin and insulin like growth factor levels, which stimulate glycogen synthesis, fat deposition, and fetal growth. Moreover, neonates of diabetic mothers of the same birth weight are at higher risk for shoulder dystocia compared to those of nondiabetic mothers because of different distributions of body fat ${ }^{(4)}$.

Despite its clinical value, accurate estimation of fetal weight and prediction of macrosomia are challenging, with substantial margins of error for both clinical estimates and routine 2dimensional (2D) sonographic biometry, especially at the extremes of fetal weight. Advances in 3-dimensional (3D) sonography have shown promise in improving fetal weight estimation over 2D sonography ${ }^{(\mathbf{1 0})}$.

Although fractional thigh volume has been shown to be a good predictor of neonatal fat in crosssectional studies and in fetuses with growth restriction, the relationship of thigh volume with estimated fetal weight and neonatal fat has not been specifically evaluated in fetuses suspected to be macrosomic. There are limited data on the performance of 3D sonography for predicting macrosomia in diabetic pregnancies (11). In our study, the aim is to test the hypothesis that incorporating 3D fractional thigh volume would be superior to conventional 2D biometry for predicting birth weight and macrosomia in diabetic pregnancies.

Our study showed that the age of the studied group ranged from 24 to 35 years with mean of 29.6 years. Regarding parity, $45 \%$ of cases were primiparous and $55 \%$ of them were multiparous. The mean gestational ages at sonographic biometry and delivery were 36.9 and 38.8 weeks, respectively. Tuuli et $\boldsymbol{a l} .{ }^{(5)}$ found that the mean gestational ages at sonographic biometry and delivery were 37.5 and 39.5 weeks, respectively.

In our study, one-fifth of the patients had macrosomia, and four fifths had no macrosomia. There were no statistical significant differences between macrosomia group and no macrosomia group in maternal age, parity, body mass index, obesity, diabetes, gestational age and gestational age at delivery. Tuuli $\boldsymbol{e t} \boldsymbol{a l} \cdot{ }^{\left(\mathbf{5}^{5}\right.}$ found that there were no 
significant differences in baseline characteristic between women with and those without a macrosomic neonate.

In our study, the mean \pm SD was lower for the 2D than the 3D projected estimate. Tuuli et al. ${ }^{(\mathbf{5})}$ found that the mean percentage error was significantly lower for the $2 \mathrm{D}$ than the $3 \mathrm{D}$ projectedestimate $(1.0 \%$ versus $12.0 \%)$. The standard deviation of the mean percentage error was also significantly lower for the 2D projected estimate (10.2\% versus $17.2 \%)$.

Our study showedthat there were statistical high significant regarding birth weight at delivery and difference from 2D/3D ( 100.001$)$. Tuuli et al. $^{(5)}$ showed a lower mean difference between the projected estimates and birth weight for 2D biometry (14.9 versus $402.33 \mathrm{~g}, \mathrm{p}<0.01$ ) and the standard deviation of the mean difference was significantly lower for the 2D projected estimates (373.8 versus $624.1 \mathrm{~g}, \mathrm{p}<$ 0.01 ), suggesting overall better agreement between the 2D projected estimates and birth weight.

Our study showed that there were statistically high significant positive correlations between estimated weight 2D and 3D and birth weight ( $\mathrm{p}<$ 0.001). The sensitivity, specificity, PPV, NPV and accuracy for predicting macrosomia> $4000 \mathrm{gm}$ in diabetic pregnancies were $81.3 \%, 78.9 \%, 49.1 \%$, $94.4 \%$ and $79.3 \%$ for 2D biometry and $78.1 \%, 77.3 \%$, $46.3 \%, 93.4 \%$ and $77.5 \%$ for 3D biometry. The sensitivity, specificity, PPV, NPV and accuracy for predicting macrosomia $>4500 \mathrm{gm}$ in diabetic pregnancies were $69.2 \%, 89.1 \%, 36 \%, 97 \%$ and $87.5 \%$ for 2D biometry and $76.9 \%, 88.4 \%, 37 \%, 97.7 \%$ and $87.5 \%$ for 3D biometry.

Tuuli et $\boldsymbol{a l} .{ }^{(5)}$ stated that seventeen of the 115 women (14.8\%) delivered macrosomic neonates with birth weights of $4000 \mathrm{~g}$ or higher (primary outcome). Two-dimensional biometry was overall superior to $3 \mathrm{D}$ biometry for predicting macrosomia. The associated specificity for predicting macrosomia was significantly higher for $2 \mathrm{D}$ biometry $(85 \%$ versus $66 \% ; P<0.01)$. Sensitivity was nominally higher for 3D sonography, but the difference was not statistically significant $(59 \%$ versus $71 \% ; P=.22$; Table 2$)$. The PPVs (40\% versus $27 \%$ ) and NPVs (92\% versus 93\%) were not significantly different for the two methods.

Similar to our study, Pagani et al. ${ }^{(\mathbf{1 1})}$ found no differences in sensitivity for predicting macrosomia. However, in contrast to our study, they found that the 3D Lee formula (not the 2D Hadlock formula) had lower systematic bias and higher specificity for predicting macrosomia. It is unclear why our results differed from those of Pagani et al. ${ }^{(11)}$ with regard to systematic bias and random error for predicting birth weight and specificity for macrosomia.

Kehl et al. ${ }^{(\mathbf{1 2})}$ developed a formula for optimal fetal weight estimation with an AC $36 \mathrm{~cm}$. Furthermore, in order to increase the accuracy of the fetal estimated weight, serial biometric measurements could be used to generate an individual antenatal growth curve. Repeated measurement of fetal AC led to prediction of a birth weight above the 90th percentile with $84 \%$ sensitivity and $100 \%$ specificity.

Garabedian et $\boldsymbol{a l}^{(\mathbf{1 3 )}}$ evaluated soft-tissue and liver measurements longitudinally through the second and third trimesters as predictive markers of macrosomia in women with pregestational diabetes. They concluded that measurement of subcutaneous tissue on a 34-week ultrasound scan in fetuses with diabetic mothers appears to be a useful supplementary tool for the detection of macrosomia.

Gibson et $\boldsymbol{a l}^{(\mathbf{1 4 )}}$ described the prenatally determined sonographic parameters that best predict birth weight and neonatal fat in fetuses suspected to be macrosomic. They concluded that fractional thigh volume was the best sonographic estimate of neonatal percent body fat and birth weight Z-score. Tuuli $\boldsymbol{e t}$ al. ${ }^{(5)}$ showed that the Hadlock 2D formula was superior to the 3D method for predicting birth weight and macrosomia in diabetic women when used approximately 2 weeks before delivery, based on the gestation-adjusted projection method

Thus, it is likely that better quantification of specific fetal soft tissue such as fat would allow for improved estimation of birth weight and prediction of macrosomia.

\section{CONCLUSION}

The Hadlock's 2D formula method was superior to $3 \mathrm{D}$ for predicting birth weight and macrosomia in diabetic women when used approximately 2 weeks before delivery, based on the gestation adjusted projection method.

We suggest that 2D sonography should remain the standard of care for predicting birth weight and macrosomia in diabetic pregnancies.

In conclusion, incorporating $2 \mathrm{D}$ may be superior to 3D fractional thigh conventional biometry for predicting birth weight and macrosomia in diabetic pregnancies.

\section{RECOMMENDATIONS}

1. It is recommended that similar studies should be done on larger number of patients.

2. Further studies should include a larger sample size and determine whether quantification of specific fetal soft tissue such as fat and addition of patient characteristics will improve prediction of macrosomia.

3. More training courses should be done for obstetricians and radiologists to improve their performance in diagnosis of fetal weight. 


\section{REFERENCES}

1. Kayem G, Grange G, Breart et al. (2009): Comparison of fundal height measurement and sonographically measured fetal abdominal circumference in the prediction of high and low birth weight at term. Ultrasound Obstet Gynecol., 34: 566-571.

2. Callaghan BC, Little AA, Feldman EL et al. (2012): Enhanced glucose control for preventing and treating diabetic neuropathy. Cochrane Database Syst Rev., 6:4349.

3. Peterson C, Grosse SD, Li R et al. (2015): Preventable health and cost burden of adverse birth outcomes associated with pregestational diabetes in the United States. Am J Obstet Gynecol., 212: 74-83.

4. Mondestin MA, Ananth CV, Smulian JC et al. (2002): Birth weight and fetal death in the United States: the effect of maternal diabetes during pregnancy. Am J Obstet Gyneco., 187:922-926.

5. Tuuli MG, Kapalka K, Macones GA et al. (2016): Three- versus two-dimensional sonographic biometry for predicting birth weight and macrosomia in diabetic pregnancies. J Ultrasound Med., 35: 1925-1930.

6. Schild RL, Fimmers R, Hansmann M (2000): Fetal weight estimation by three-dimensional ultrasound. Ultrasound Obstet Gynecol., 16: 445-452.

7. Lee W, Balasubramaniam M, Deter RL et al. (2009): New fetal weight estimation models using fractional limb volume. Ultrasound Obstet Gynecol., 34: 556-565.

8. Kurmanavicius $\mathrm{J}$, Burkhardt $\mathrm{T}$, Wisser $\mathrm{J}$ et al. (2004): Ultrasonographic fetal weight estimation: accuracy of formulas and accuracy of examiners by birth weight from 500 to 5,000 g. J Perinat Med., 32: 155-161.

9. Ben-Haroush A, Melamed $\mathbf{N}$, Mashiach $\mathbf{R}$ et al. (2008): Use of the Amniotic Fluid Index Combined With Estimated Fetal Weight Within 10 Days of Delivery for Prediction of Macrosomia at Birth. J Ultrasound Med., 27:1029-32.

10.Scioscia M, Vimercati A, Ceci O et al. (2008): Estimation of birth weight by two-dimensional ultrasonography: a critical appraisal of its accuracy. Obstet Gynecol., 111: 57-65.

11.Pagani G, Palai N, Zatti S et al. (2014): Fetal weight estimation in gestational diabetic pregnancies: comparison between conventional and threedimensional fractional thigh volume methods using gestation-adjusted projection. Ultrasound Obstet Gynecol., 43:72-76.

12.Kehl S, Korber C, Hart $\mathrm{N}$ et al. (2012): New sonographic method for fetuses with a large abdominal circumference improves fetal weight estimation. Ultraschall Med., 33: 265-269.

13. Garabedian C, Vambergue A, Salleron J et al. (2013): Prediction of macrosomia by serial sonographic measurements of fetal soft-tissues and the liver in women with pregestational diabetes. Diabetes and Amp Metabolism, 39(6): 511-518.

14. Gibson KS, Stetzer B, Catalano PM et al. (2016): Comparison of 2- and 3-dimensional sonography for estimation of birth weight and neonatal adiposity in the setting of suspected fetal macrosomia. J Ultrasound Med., 35: 1123-1129. 